УДК 821.161.1; 82-312.7

DOI 10.23951/1609-624X-2020-5-174-180

\title{
СКАЗОЧНЫЙ ИНТЕРТЕКСТ В РОМАНЕ ЛЕНЫ ЭЛТАНГ «КАМЕННЫЕ КЛЕНЫ» (ЧАСТЬ ВТОРАЯ)
}

\section{О. П. Величко, Е. А. Полева}

\section{Томский государственный педагогический университет, Томск}

\begin{abstract}
Введение. Статья является продолжением ранее начатого исследования интертекстуальности в романе «Каменные клены» современного писателя Лены Элтанг. В первой части предметом анализа были аллюзивные соотнесения сюжетной линии Саши Сонли с мотивами фольклорной сказки о женской инициации. Во второй части мы обращаемся к интертекстуальному анализу сюжетной линии центрального героя Луэллина и художественного пространства романа.

Цель статьи - выявить семантику и функции сказочного интертекста в модернистском романе Лены Элтанг «Каменные клены».

Материал и методы. Материалом исследования послужил роман Лены Элтанг «Каменные клены». В работе применен интертекстуальный и мотивный анализ с опорой на работы И. Смирнова, М. Гаспарова, Б. Гаспарова, И. Паперно. Также теоретической базой являются труды О. М. Фрейденберг, В. Я. Проппа, Е. Н. Елеонской, Дж. Фрэзера и других исследователей, посвященные изучению мотивной структуры фольклорных сказок.

Результаты и обсуждение. Сюжетная линия центрального героя Луэллина, как и линия Саши, организована в соответствии со сказочным сюжетом инициации (непослушание и отъединение от отца, смена фамилии, отгадывание загадок/прохождение испытаний для воссоединения с суженой при помощи волшебных помощников, хождение за море/в загробный мир, возвращение к возлюбленной). Сказочный интертекст проявляется на уровне художественного пространства: «Каменные клены» (дом-гостиница семьи Сонли) аллюзивно связан с образом «окаменелого», заколдованного царства, дом умершего отца Луэллина - с загробным царством.

Заключение. Важным ресурсом моделирования художественного мира Элтанг являются фольклорные тексты. При использовании сказочных мотивов автор использует и фольклористскую, и психоаналитическую их семантику. Элтанг интересует личность, переживающая происходящее с ней в двух изменениях: профаннобытовом (этико-психологическом) и сакральном. Центральные герои романа проживают психологически уникальный опыт прохождения вечного, неизменного по своей сути сюжета инициации, и это вписывает их частную жизнь в большое, вечно повторяющееся время-пространство сказки (мифа).
\end{abstract}

Ключевые слова: современный модернизм, литература русской эмиграции, интертекст, сказочные образы и мотивы, инициация, Лена Элтанг.

\section{Введение}

В первой части статьи представлены результаты анализа интертекстуальных связей сюжетной линии Саши Сонли, героини романа Лены Элтанг «Каменные клены», с мотивами фольклорной сказки о женской инициации [1]. Вторая часть посвящена интертекстуальному анализу сюжетной линии центрального героя Луэллина (Лу) и художественного пространства романа.

\section{Материал и методы}

Теоретико-методологической базой исследования являются работы по интертекстуальному и мотивному анализу Б. Гаспарова и И. Паперно $[2,3]$, И. Смирнова [4], М. Гаспарова [5, 6]. В понимании семантики сказочных мотивов мы опираемся, прежде всего, на труды В.Я. Проппа [7], О. М. Фрейденберг [8, 9], Е. Н. Елеонской [10].

Цель работы - выявить семантику и механизмы функционирования сказочного интертекста в модернистском романе Лены Элтанг «Каменные клены» [11].

\section{Результаты и обсуждение}

Сюжет мужской инициации в сказках связан с поиском суженой и решением возникающих на этом пути трудностей. Инициальные мотивы вариативны, основные из них - разгадывание загадок, вызволение суженой из обстоятельств/состояний, включающих семантику смерти: расколдовывание царства, объятого сном, снятие чар/заклятий, наложенных Кощеем Бессмертным (другими персонификациями сил смерти/зла) и т. п. Инициальный сюжет предполагает хождение в Тридесятое царство и победу над смертью. В ряде случаев сам герой может быть заколдованным (мотив оборотничества в сказке $[12,13])$, тогда инициация состоится при условии либо внутреннего изменения самого героя-протагониста, либо его в ненастоящем обличии должна полюбить (и таким образом расколдовать) будущая невеста.

Аллюзивные отсылки к этим инициальным мотивам системно и комплексно проявляются в «Каменных кленах». Проанализируем специфику их функционирования в романном нарративе.

Фольклорная сказка не знает различия сюжета и фабулы, о событиях повествуется в прямой временной, причинно-следственной последовательности. Иной ресурс у романа, тем более модернистского, в котором повествование отражает поток сознания и рефлексию персонажей, воспринимаю- 
щих социальные отношения как связанные с личным прошлым и универсальным временем-пространством мифа и сказки. «Античный мусор» [11, c. 99], «античные эпизоды» [11, с. 354] - призма, через которую оба центральных героя романа, Саша Сонли и Луэллин Элдербери, воспринимают себя и происходящие с ними события. Дневниковая наррация, передающая специфику сознания двух фокальных персонажей, отражает процесс их инициации, который многократно перезапускается/осложняется/затягивается.

Важно учесть, что в интерпретации происходящего с героями наряду с фольклорно-мифологической важна психоаналитическая семантизация их действий. Психоаналитическую призму восприятия поступков задают сами герои: Луэллин называет постоянными спутниками (своими и Саши) страх и вину; он вынужден посещать психотерапевта после аварии, в которой был виновником увечья не только собственного, но и отца Саши; вина Луэллина персонифицирована в образе призраков двух отцов - его и Саши (плотника и суконщุика); Саша объясняет сокрытие своего дневника в земле, ссылаясь на фрейдовскую трактовку поступка $[11$, с. $321,349,351]$ и др.

Завязка сюжетной линии Луэллина оформлена как детективная интрига: он заключает пари с плотником и суконщчиком в «небесном саду» ${ }^{1}$, что за три дня разгадает тайну одной из девушек городка Вишгарда, проживающей в усадьбе-гостинице «Каменные клены». Местные жители обвиняют ее в колдовстве и убийстве сводной сестры.

Луэллин не знал имени девушки и понял, что он соучастник в ее судьбе, только когда увидел на дверях пансиона табличку с фамилией Сонли - человека, пострадавшего по его вине в аварии: «...эта табличка будто по глазу меня полоснула горячим медным краем, и глаз залился кровью, а рука заныла в том месте, где сломалась двенадцать лет назад... вот так-то, бузинный дядюшка лу» (здесь и далее сохранена авторская орфография, отражающая специфику письма героя. - О. В., Е. П.) [11, с. 142].

Плотник и суконщчик могут быть интерпретированы как голоса интуиции Луэллина и как фантомы, порожденные его бессознательным (они являются, когда Лу находится в опьянении, т. е. измененном состоянии сознания). При этом призраки двух отцов знают будущее (что не доступно самому герою) и выступают в роли волшебных помощников, направляя Луэллина в «Каменные клены», предупреждая, что нужно вовремя вернуть дневник-травник, украденный у Саши, конкретно опи-

\footnotetext{
1 Луэллин пишет в дневнике, не используя заглавные буквы и кавычки, что обеспечивает двойную семантизацию небесного сада: как названия паба, и как надматериального мира, в котором он разговаривает с призраками.
}

сывают ему последствия ослушания их советов. Тем не менее Луэллин не вполне доверяет их голосам, спорит с ними, оттягивает возвращение в «Клены» после того, как украл у Саши дневниктравник. Это недоверие Луэллина, с одной стороны, иллюстрирует сквозную в романе Элтанг идею о том, что иррационально полученное знание своей судьбы не отменяет личного выбора, ошибочных поступков и, в конечном счете, вины и ответственности за происходящее. С другой стороны, свобода человека - свобода в границах уже известных, вечных сюжетов, метафорически описывающих онтологически обусловленные узловые события индивидуальной жизни.

Проявленные в дневнике состояния и семантика локусов пребывания Луэллина отражают положение пограничности - между прошлым и будущим, явью и фантомным миром призраков, жизнью и смертью. Он часто находится в состоянии алкогольного опьянения, в полусне, живет мнимой жизнью: изменяет свою фамилию; получив запрет на преподавание античной истории, работает учителем в автошколе, отрабатывая на мнимой машине, по мнимым дорогам правила езды, которые он роковым образом однажды нарушил. Работа в автошколе и закрепляет цикличную модель времени, так как Луэллин постоянно проживает состояние езды по дороге, приведшее к травме, и указывает на интенцию исправить прошлое, хотя бы в фиктивном мире занять позицию не нарушителя, а учителя, корректирующего ошибки других.

Локусы пребывания Луэллина - «Каменные клены», небесныци сад, лондонская квартира, дом отца за морем в Ирландии - объединены семантикой сна/измененного состояния сознания/смерти. Лондонская квартира напоминает нежилую (в ней завяли цветы, умерли птички, скисло вино). Его соседка пишет: «Но что-то было в этом нежилое знаешь, как в домах, которые сдаются после смерти владельца» [11, с. 343]. Суконщзик вопрошает: «сам-то ты на каком свете?» [11, с. 268].

«Каменные клены» связаны с прошлым Луэллина, от которого он хотел бы скрыться, чтобы избыть чувство вины. Но, заключив пари с двумя отцами, он вынужден войти в это пространство, чтобы разгадать тайну его нынешней владелицы, давшей себе обет молчания. И созвучие фамилии Саши со сном (Сон-ли), и ее пребывание в молчании (в мифологии оно синонимично смерти [8]), и название усадьбы - все отсылает к образу заколдованного/окаменелого царства. Ассоциацию с этим сказочным образом обозначает сама Саша, пытаясь разгадать, почему мама именно так назвала родовое имение: «...клен - это заколдованный человек, закрывающий лицо пятипалыми листьями» [11, c. 381]. 
Приход Луэллина в «Каменные клены» с целью разгадать тайну живущей там молчаливой девушки соотносится с мотивом расколдовывания подлинным женихом невесты и всего сонного царства. Эта мысль подтверждается множеством прямых параллелей со сказочными мотивами и атрибутикой. Прежде всего, Луэллин многократно маркирован как избранный герой. Дневник Луэллина начинается с детского воспоминания о «поцелуе в макушку» во время отбывания наказания в школе. Этот поцелуй («самое острое плотское переживание») соотносится с благословением (идиома «поцелованный в маковку»), оставленным кем-то незримым во время его сна/забытья: «...я открыл глаза... неизвестно чей поцелуй горел на моем темени» $[11$, c. 10].

По утверждению В. Я. Проппа, в сказке избранность героя маркирована наличием у него волшебных помощников из загробного мира [9]. У Луэллина их два - призраки его отца и отца Саши. Кроме этого, он пришел в «Клены» «через вествудский лес», который в сказке отделяет свое пространство от чужого, является местом инициации [9]. Наконец, действие героя на чужой ему изначально территории будущей жены - принципиально для сказки. Джеймс Фрэзер отметил, что сказочный герой почти никогда не наследует царства своего отца, он приходит в чужую землю, решает трудные задачи, женится на царевне и остается там царствовать: «...на определенной стадии общественного развития, по-видимому, было обычным явлением видеть продолжателей царского рода не в мужчинах, а в женщинах и в каждом последующем поколении отдавать царство мужчине из другой семьи, нередко из другой страны. В народных сказках... варьируется сюжет о человеке, пришедшем в чужую страну, который завоевывает руку царской дочери, a с ней половину или все царство» [14]. Итак, его изначальная интенция прихода в «Каменные клены» - разгадать тайну - напрямую соотносится со сказочным мотивом отгадывания загадок невесты и снятия злых чар.

Заметим, что и автомобильная катастрофа по вине Луэллина, приведшая к болезни, а затем и смерти Уолдо Сонли, аллюзивно связана со сказочным мотивом умерщвления женихом старого царя/ победы над ним. Плотник - отец невесты, заплативший за посвящение героя своей жизнью, а значит, имеет право на предварительное испытание жениха. Плотник и суконщик действуют сообща, выступая в функции волшебных помощников соединения двух родов.

«Логика» сказки корректирует этико-психологическую семантику фабульных событий романа. Психологически герой переживает случившееся с отцом Саши как свою вину, а онтологически это оправдано движением самой жизни: для мужской инициации необходима победа над «старым царем» и осознание своей ответственности за оставшуюся после этой победы сироту. Плотник (отец Саши) Луэллину говорит прямо: «не забывай, что мы говорим о круглой сироте», на что суконщик «важно произносит»: «не благородный ли муж тот, кто воспитает сироту ростом в шесть чи?» ${ }^{1}$ (курсив Элтанг. - О. В., Е. П.) [11, с. 268]. Суконщик цитирует слова ученика Конфуция Цзэнцзы, рассуждающего о том, кого можно назвать благородным мужем, достойным правителем: воспитавшему сироту можно доверить и царствование [15]. Рост сироты в суждении философа указывает на детский возраст; в романе же Саше 33-34 года, но она маленького роста, как ребенок нуждается в защите. Философский интертекст не отменяет аллюзий на сказку, в которой покровительство жениха девушке-сироте принципиально значимо.

Наконец, появление Луэллина предвидела обладающая даром ясновидения мама Саши (некто «явится с ирландской стороны и все в нашей жизни изменит» $[11,231])$; еще когда Саша была ребенком, «руны предсказали ей двух мужей: одного мужа, который заложит свой слух, как Хеймдалль, и другого, который заложит свой глаз, как Один» $[11$, с. 52]. Луэллин имеет характерную метку, которую получил фактически от отца Саши: во время автомобильной аварии он потерял глаз.

Саша замечает, что у него разные глаза: «Увидев его лицо, я чуть было ключи не выронила» [11, c. 69], но не сразу узнает своего суженого. Предсказание о двух мужьях не содержит конкретизации, какой из женихов - подлинный, поэтому и глухой на одно ухо Сондерс Брана, и полуслепой Луэллин подвергаются испытаниям невесты ${ }^{2}$, среди которых игра в прятки (Саша прячет травник в земле и подозревает в краже их обоих), испытание неподлинным (оборотным) видом невесты (Саша запутывает Луэллина, в дневнике описывая не совершенные ею преступления, и в финале он справляется с испытанием - готов связать с ней жизнь, поддержать ее, даже если она является чудовищем=убийцей).

Элтанг использует сказочный мотив неузнанности героя/подлинного жениха, который синоними-

\footnotetext{
${ }^{1}$ Этот пример демонстрирует авторскую стратегию интертекстуальности. В целом фольклорный, литературный, философско-культурологический интертексты равноправно формируют образы центральных героев. Сказочный интертекст нами выделяется условно, в границах конкретных исследовательских задач.

2 Приведем мнение В. Я. Проппа: «Раньше, чем получить руку царевны, герой подвергается различным испытаниям, которые он может выполнить только тогда, если он прошел весь путь, канонический для героя, т. е. если он имеет волшебного помощника и обладает магическими средствами и силами» [9]. При этом, отметила О. М. Фрейденберг, «в сказке тот, кто не может ответить на загадку, умирает, а тот, кто отвечает на нее, получает спасение и победу» $[8$, c. 126]
} 
чен мотиву оборотничества (пребывания не в своем облике) и означает состояние мнимой смерти․․ Оборотничество Луэллина проявляется в ряде деталей. Во-первых, благодаря внешнему виду и одежде его принимают за другого - инспектора полиции: «...инспектор? нет, я все-таки ужасно похож на полицейского - надо купить новый плащ...» [11, с. 201]. Приезжая к Саше в финале как к своей избранной, Луэллин признается, что устал врать, просит прощение и снимает плащ, что означает разоблачение, открытие себя подлинного. Его откровение «расколдовывает» Сашу, она отвечает Луэллину, возвращается к речиㄹ․

Во-вторых, герой меняет свою фамилию, что объясняется, на профанном уровне, сложными отношениями с родителями и с самим собой. В этом жесте подчеркивается отречение от отца из-за обиды (отец ушел из семьи и прекратил общение с сыном), а также стремление после аварии обнулить прежнюю жизнь, как бы начать другою, скрывшись от себя прежнего. Психологические причины герой осознает, вопрошая сам себя: «...может быть, поменяв свое имя с костяники на бузину, ты не только спрятался, но и вовсе исчез?» [11, с. 195]. Луэллин «спрятался» за новым именованием, и это дает ему возможность не быть опознанным Сашей в качестве человека, виновного в болезни и смерти ее отца.

Функциональна семантика прежней и новой фамилии героя - она отражает сущностные, незримые связи Луэллина с семьей Сонли ${ }^{3}$ Фамилию

${ }^{1}$ В сказке и мифе мотив оборотничества «связан с переходными обрядами (обряд инициации и воспроизводящий некоторые его черты свадебный обряд), санкционирующими перемену состояния человека, что интерпретируется как смерть в одном статусе и рождение в другом. В фольклорно-мисоологических сюжетах, отражающих переходные обряды (особенно свадебный), мотивом оборотничества передается перемена статуса, сопровождающая пересечение пространственных и временных рубежей: при прибытии в место обитания своей суженой...», границу загробного царства [12].

${ }^{2}$ Отдельно отметим, что в финале Луэллин считает, что проиграл пари, так и не разгадав тайну Саши Сонли, но выясняется, что его задача была в ином - не открыть все секреты Саши, а полюбить ее, принять как свою суженную и войти в ее дом как в свой, что он интуитивно предчувствовал: «...чувствую себя улиссом у ворот пенелопы, обнаружившим, что он воевал только десять лет, а другие десять лет, как последний дурак, добирался домой» [11, с. 170]. Но совершил только в финале.

${ }^{3}$ Ассоциативные соотнесения фамилии Луэллина с пространством жизни Саши дополняют множество иных параллелей: они оба сироты, у обоих умерли матери, которых называли ведьмами (Саша - дочь «русской ведьмы», Луэллин - «ведьмин внучок», так как его маму одноклассники принимали за бабушку). Оба пережили травму отдаления отца (у Луэллина отец ушел из семьи и не общался с ним, отец Саши женится на другой женщине после смерти матери), а затем и его смерть. Оба воспринимают ассоциируют себя и события свой жизни со сказочно-мифологическими и литературными образами и сюжетами.
Стоунбери (костяника, буквально с английского «каменная ягода»), которая прямо соотносится с названием усадьбы «Каменные клены» (и то, и другое - каменные растения), Луэллин меняет на Элдербери - бузинная ягода, «ведьмино дерево» (Сашу называют ведьмой), наделенное свойством врачевать, утешать: «...бузина, греческая дудочка, руна Fehu - чай из ее цветов очищает кровь, а отвар из коры успокаивает сердце» [11, с. 69]. Исконная фамилия Лу, как и усадьба Сонли, отражают единство противоположностей и «дух противоречия» [11, с. 381], соединяя мертвое (камень) и живое (ягода/клен), прочное и хрупкое, уязвимое.

Смена фамилии героем соотносится с элементом инициального действия - сокрытия себя под другим именем как пребывания в другой «шкуре» и отъединение от своего рода. В письме-завещании отец Луэллина пишет: «Дорогой мой сын, ... в одной китайской книге сказано, что овиьь на севере вырастают прямо из земли, ... а пуповина у них уходит глубоко в землю, и перерезать ее нельзя можно только заставить ее порваться, напугав ягненка громким криком, чтобы он побежал, в стадо такой ягненок уже не вернется, но станет пастись поодаль, покуда не повзрослеет

я напугал тебя громким криком и порвал твою пуповину, и вот уже двадиать восемь лет как ть пасешься в стороне, не желая признавать меня родней - не пора ли тебе повзрослеть?» (курсив Элтанг. - O. B., E. П.) [11, с. 66]. Отец этап отъединения от семьи интерпретирует как переходный возраст, взрослость же связывает с возвращением к своему роду.

По утверждению В. Я. Проппа, волшебная сказка отражает отношения внутри своего рода и отношение родов жениха и невесты [9]. Ослушание отца в сказке знаменует стадию отъединения сына от своего рода и «запускает» сюжет инициации. В романе этому соответствуют отречения Луэллина от фамилии и отказ вступать в наследство. Но в финале сказки самостоятельный, не нуждающийся в родительской опеке герой возвращается в отчий дом или воцаряется во владениях своей невесты/ жены. Предшествует возвращению победа над смертью.

В романе Луэллин, не имея терпения, ворует Травник Саши и, игнорируя советы волшебных помощников, не возвращает его вовремя на место, что соотносится поступком протагониста в сказке, преждевременно раскрывающего секрет своей суженой и забирающего у нее что-либо, защищающее от беды (шкурку лягушки или материнский оберег). Для исправления ситуации требуется отправка в загробное царство.

Луэллин осознает необходимость вернуть Саше травник, но вместо этого он наконец-то отправля- 
ется в Ирландию, в дом отца. Это заморское пространство, отмеченное семантикой смерти (там умер отец), низа и сумерек/темноты. Отец умер, сорвавшись с лестницы, ведущей вниз (это многократно подчеркнуто в повествовании), в темный подвал [11, с. 122]. Но главное, что именно после посещения дома отца Луэллин лишается волшебных помощников и возвращается в «Каменные клены» раскрыться Саше.

В романе, как и в сказке, волшебный помощник исчезает после того, как инициация свершилась. Вначале призраки перестали отвечать Луэллину: «...между прочим, ни тот, ни другой мне не ответили, раньше такого не случалось - что-то меняется и мне становится немного не по себе» [11, с. 201], а затем стали являться «без предупреждения» и настойчиво требовать исполнения их воли; «говорю же: что-то меняется» [11, с. 265], - резюмирует Луэллин. Изменение отношений с отцами являются знаками готовности героя к новой стадии инициации. Ее конкретно обозначает суконщик, внезапно явившийся в его квартиру: «...пора тебе... жениться, на худой конец, луэллин стоунбери!» ${ }^{1}[11$, с. 265]. И вернувшись из Ирландии к Саше Луэллин, описывает свое состояние освобождения от призраков прошлого, чувство обновления, перерождения, готовности к жизни: «...теперь, когда я вернулся оттуда, мне так странно и свежо <..> слушайте, саша, это важно, я был там! я был в бэксфорде, на этом острове яблок, нет там никаких яблок ${ }^{2}$, зато есть могила моего отца, я был там, и теперь они оба оставили меня в покое - и суконщик, и плотник, слышите - оба!» [11, с. 390-391].

В ответ на свою исповедь и покаяние (он говорит о том, что плотник и суконщик персонифицировали два его греха: «...небрежение, и это ваш отец... непрощение, и это мой отец» [11, с. 389]) Луэллин требует от Саши ответного слова («да говорите же со мной» $[11$, с. 391]). Их взаимная речь, диалог сопровождают процесс рождения новой жизни (Саша принимает роды у собаки). Так в финале утверждается семантика пробуждения к жизни после завершения инициальных испытаний.

\section{Заключение}

Мотив инициального испытания объединяет сюжетные линии центральных героев. Не только Саша заколдована (Луэллин называет ее «подменышем» из славянской мифологии [11, с. 265] и мнимый жених Брана сравнивает с «подменышем из холма» $[11$, с. 325$]$; она находится в состоянии временной смерти-молчания), но заколдован и он сам. Элтанг использует реверсивность, незнакомую сказке: одновременно и невеста, и жених нуждаются во взаимной помощи, в вызволении из состояния мнимой/временной смерти.

Архетипические ситуации психологически индивидуально переживаются героями - таков основной прием использования Элтанг сказочного интертекста в романе. Он обеспечивает реверсивность «личного, уникального» и «общинного, универсального» опыта.

Анализ интертекстуального уровня романа позволят утверждать, что для Лены Элтанг важным сематическим ресурсом для моделирования художественного мира являются фольклорные тексты. Элтанг интересует личность, проживающая происходящее с ней в двух изменениях: профанно-бытовом (этико-психологическом) и сакральном. Коллизии современного человека (самоопределение, отношение с родителями, поиск своей второй половины) повторяют вечные, неизменные по своей сути сюжеты инициации; частный опыт оказывается частью большого время-пространства сказки (мифа).

\section{Список литературы}

1. Полева Е. А., Величко О. П. Сказочный интертекст в романе Лены Элтанг «Каменные клены» // Вестн. Томского гос. пед. ун-та (TSPU Bulletin). 2020. Вып. 3 (209). C. 53-62. DOI: 10.23951/1609-624X-2020-3-53-62.

2. Гаспаров Б. М. Литературные лейтмотивы. Очерки по русской литературе XX века. М.: Наука, 1994. 303 [1] c.

3. Гаспаров Б., Паперно И. К описанию мотивной структуры лирики Пушкина // Russian Romanticism: Studies in the Poetic Codes. Stockholm, 1979. C. 9-44.

4. Смирнов И. П. Порождение интертекста. Элементы интертекстуального анализа с примерами из творчества Б. Л. Пастернака. 2-е изд. СПб.: Языковый центр СПбГУ, 1995. 189 с.

5. Гаспаров М. Л. Литературный интертекст и языковой интертекст // Известия АН. Серия лит. и яз. 2002. Т. 61, № 4. С. 3-9.

6. Гаспаров М. Л. Парафраз и интертекст. URL: https://www.ruthenia.ru/document/470280.html (дата обращения: 25.12.2019).

7. Пропп В. Я. Исторические корни волшебной сказки. М.: Лабиринт, 1998. 512 c. URL: https://bookscafe.net/read/propp_ vladimir-istoricheskie_korni_volshebnoy_skazki-22520.html\#p104 (дата обращения: 12.01.2020).

8. Фрейденберг О. М. Миф и литература древности. 2-е изд. М.: Вост. лит., 1998. 800 c. URL: http://www.fedy-diary.ru/ html/102010/18102010-01b.html (дата обращения: 25.12.2019).

\footnotetext{
${ }^{1}$ Отметим, что отец Лу называет его прежней фамилией, т. е. маркирует причастность к своему роду.

${ }^{2}$ Отсылка к сказочно-мифологическому образу яблока здесь также семантически нагружена.
} 
9. Фрейденберг О. М. Поэтика сюжета и жанра. М.: Лабиринт, 1997. 448 с.

10. Елеонская Е. Н. Сказка о Василисе Прекрасной и группа однородных с нею сказок // Сказка, заговор и колдовство в России: сб. тр. М.: Индрик, 1994. С. 42-50. URL: https://yagaya-baba.ru/2018/05/06/10397.html (дата обращения: 10.01.2020).

11. Элтанг Л. Каменные клены: роман. М.: АСТ: Астрель, 2009. 414 с.

12. Мифы народов мира: энциклопедия: в 2 т. Т. 2. К (Корибанты) - Я / гл. ред. С. А. Токарев. М.: Сов. энциклопедия, 1988. 671 c. URL: https://www.gumer.info/bibliotek_Buks/Mifologia/index.php (дата обращения: 23.02.2020).

13. Борисова Е. А. Оборотничество в русской волшебной сказке. URL: https://svart-ulfr.livejournal.com/428442.html (дата обращения: 12.01.2020).

14. Фрэзер Дж. Золотая ветвь. Исследование магии и религии. URL: https://www.litmir.me/br/?b=9176\&p=1 (дата обращения: 10.01.2020).

15. Маслов А. Введение // Конфуций. Суждения и беседы. Ростов н/Д: Феникс, 2006. URL: https://modernlib.net/books/ konfuciy/suzhdeniya_i_besedi/read/ (дата обращения: 10.01.2020).

Величко Оксана Петровна, магистрант, Томский государственный педагогический университет (ул. Киевская, 60, Томск, Россия, 634061). E-mail: oksana_kolesnikova@list.ru

Полева Елена Александровна, кандидат филологических наук, доцент, заведующая кафедрой русской литературы, Томский государственный педагогический университет (ул. Киевская, 60, Томск, Россия, 634061). E-mail: polevaea@ sibmail.com

Материал поступил в редакичию 28.04.2020.

DOI 10.23951/1609-624X-2020-5-174-180

\section{FAIRY-TALE INTERTEXT IN LENA ELTANG'S NOVEL “STONE MAPLES” (PART 2)}

\section{O. P. Velichko, E. A. Poleva}

\section{Tomsk State Pedagogical University, Tomsk, Russian Federation}

Introduction. This article is a continuation of a previously begun study of intertextuality in the novel "Stone Maples" by contemporary writer Lena Eltang. In the first part, the subject of analysis was the allusive correlations of the storyline of Sasha Sonley with the motives of the folklore tale of female initiation. In the second part, we turn to the intertextual analysis of the plot line of the central character Luellin and the artistic space of the novel.

The purpose of the work - is to identify the semantics and functions of the fairy-tale intertext in Lena Eltang's modernist novel "Stone Maples".

Material and methods. Intertextual and motivational analysis based on the works of I. Smirnov, M. Gasparov, B. Gasparov, and I. Paperno was applied. Also, the theoretical basis of the research is the works of folklorists and psychologists devoted to the motivational structure of folklore tales about an orphan girl, the plot of initiation (O. M. Freudenberg, E. N. eleonskaya, R. Efimkin, etc.). The research material is Lena Eltang's novel "Stone Maples".

Results and discussion. Llewellyn's storyline is also organized in accordance with the fairy-tale story of initiation (disobedience and separation from the father, name change, search for the bride, guessing riddles/passing tests to reunite with the betrothed, going beyond the sea / to the afterlife, returning to the beloved).

In addition, the fairy-tale intertext is manifested at the level of artistic space: "Stone Maples" - the house-hotel of the Sonli family is allusively connected with the image of the "petrified", enchanted Kingdom. This toponymic image is correlated in the novel with allusions to a complex of fairy-tale motifs about an enchanted bride/groom.

Conclusion. An analysis of the intertextual level of the novel will allow us to state that for Lena Eltang an important sematic resource for modeling the author's art world is not only folklore texts themselves, but also scientific studies on folklore. The dialogue-strained semantic relationship with folklore allows us to isolate not the superficial correlation of the novel with a fabulous intertext, but to enter the anthroposophical concept of Eltang: she is interested in the type of personality living in what is happening to him in two changes: profane-everyday and sacred. The collisions of modern man (self-determination, relationship with Others, the search for his second half) repeat the eternal, essentially unchanged subjects of initiation.

Keywords: modernism, literature of Russian emigration, intertext, fairy-tale images and motifs, initiation, Lena Eltang.

\section{References}

1. Poleva E. F., Velichko O. P. Skazochnyy intertekst v romane Leny Eltang "Kamennye klyony" (chast' 1) [Fairy-tale intertext in Lena Eltang's novel "Stone Maples" (Part 1)]. Vestnik Tomskogo gosudarstvennogo pedagogicheskogo universiteta - TSPU Bulletin, 2020, no. 3, pp. 53-62 (in Russian). DOI: 10.23951/1609-624X-2020-3-53-62 
2. Gasparov B. M. Literaturnye leytmotivy. Ocherki po russkoy literature XX veka [Literary leitmotifs. Essays on Russian literature of the twentieth century]. Moscow, Nauka Publ., 1994. 303 p. (in Russian).

3. Gasparov B., Paperno I. K opisaniyu motivnoy struktury liriki Pushkina [To the description of the motivic structure of Pushkin's lyrics]. Russian Romanticism: Studies in the Poetic Codes. Stockholm, 1979. Pp. 9-44.

4. Smirnov I. P. Porozhdeniye interteksta. Elementy intertekstual'nogo analiza s primerami iz tvorchestva B. L. Pasternaka [The Origin of the intertext. Elements of intertextual analysis with examples from the work of B. L. Pasternak]. Saint Petersburg, Yazykovyy tsentr SpbGU Publ., 1995. 189 p. (in Russian).

5. Gasparov M. L. Literaturnyy intertekst i yazykovoy intertekst [Literary intertext and intertext language]. Izvestiya AN. Seriya literatury i yazyka, 2002, vol. 61, no. 4, pp. 3-9 (in Russian).

6. Gasparov M. L. Parafraz i intertekst [Paraphrase and intertext] (in Russian). URL: https://www.ruthenia.ru/document/470280. html (accessed 25 December 2019).

7. Propp V. Ya. Istoricheskiye korni volshebnoy skazki [Historical roots of a fairy tale]. Moscow, Labirint Publ., 1998 (in Russian). URL: https://bookscafe.net/read/propp_vladimir-istoricheskie_korni_volshebnoy_skazki-22520.html\#p104 (accessed 12 January 2020).

8. Freydenberg O. M. Mif i literatura drevnosti [Myth and literature of antiquity]. Moscow, Vostochnaya literatura Publ., 1998. 800 p. (in Russian). URL: http://www.fedy-diary.ru/html/102010/18102010-01b.html (accessed 25 December 2019).

9. Freydenberg O. M. Poetika syuzheta i zhanra [Poetics of plot and genre]. Moscow, Labirint Publ., 1997. 448 p. (in Russian).

10. Eleonskaya E. N. Skazka o Vasilise Prekrasnoy i gruppa odnorodnykh s neyu skazok [The Tale of Vasilisa the Beautiful and a group of similar tales]. Skazka, zagovor i koldovstvo v Rossii: sbornik trudov [Fairy tale, conspiracy and witchcraft in Russia: collection of works]. Moscow, Indrik Publ., 1994. Pp. 42-50 (in Russian). URL: https://yagaya-baba.ru/2018/05/06/10397.html (accessed 10 January 2020).

11. Eltang L. Kamennye klyony [Stone maples]. Moscow, AST: Astrel' Publ., 2009. 414 p. (in Russian).

12. Tokarev S. A. (ed.) Mify narodov mira: entsiklopediya: $v 2$ t. T. 2. K (Koribanty) - Ya [Myths of the peoples of the world: encyclopedia. In 2 volumes. Vol. 2]. Moscow, Sovetskaya Entsiklopediya Publ., 1988 (in Russian). URL: https://www.gumer.info/ bibliotek_Buks/Mifologia/index.php (accessed 23 February 2020).

13. Borisova E. A. Oborotnichestvo v russkoy volshebnoy skazke [Shapeshifter in the Russian fairy tale] (in Russian). URL: https:// svart-ulfr.livejournal.com/428442.html (accessed 12 January 2020).

14. Frezer Dzh. Zolotaya vetv'. Issledovaniye magii i religii [The Golden Bough. Study of magic and religion] (in Russian). URL: https://www.litmir.me/br/?b=9176\&p=1 (accessed 10 January 2020).

15. Maslov A. Vvedeniye [Introduction]. Konfutsiy. Suzhdeniya i besedy [Confucius. Judgments and conversations]. Rostov-on-Don, Feniks Publ., 2006 (in Russian). URL: https://modernlib.net/books/konfuciy/suzhdeniya_i_besedi/read/ (accessed 10 January 2020).

Poleva E. A., Candidate of Philological Sciences, Associate Professor, Head of the Department of Russian Literature Tomsk State Pedagogical University (ul. Kiyevskaya, 60, Tomsk, Russian Federation, 634061). E-mail: poleva@tspu.edu.ru

Velichko O. P., Master's Degree Student, Tomsk State Pedagogical University (ul. Kiyevskaya, 60, Tomsk, Russian Federation, 634061). E-mail: oksana_kolesnikova@list.ru 